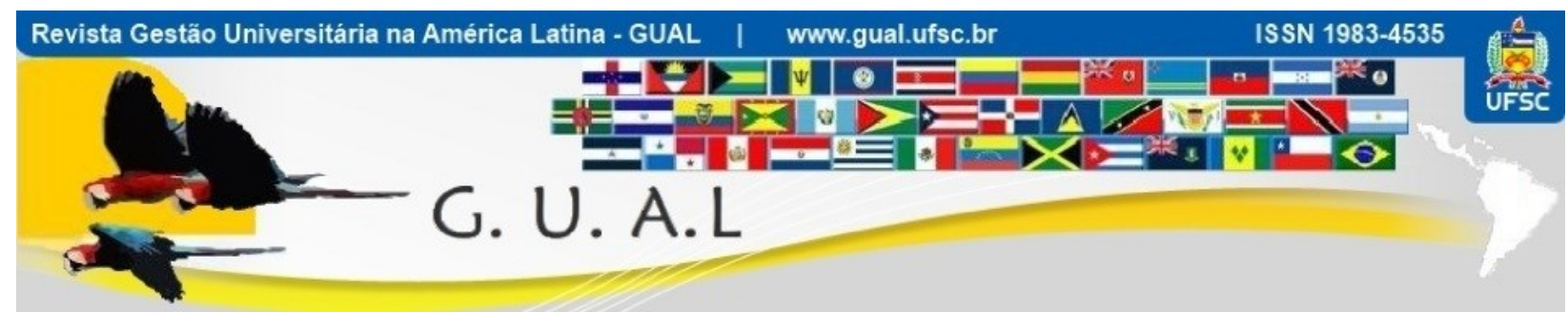

DOI: http://dx.doi.org/10.5007/1983-4535.2020v13n1p70

\title{
A TÉCNICA MULTIDIMENSIONAL DE ENSINO E OS BENEFÍCIOS PROPORCIONADOS ÀS STARTUPS LOCAIS: UMA PERSPECTIVA DOS ALUNOS
}

\section{THE MULTIDIMENSIONAL TEACHING TECHNIQUE AND THE BENEFITS PROVIDED TO LOCAL STARTUPS: A STUDENT'S PERSPECTIVE}

\author{
Andréa Aparecida da Costa Mineiro, Mestre \\ http://orcid.org/0000-0003-1155-7333 \\ andreamineiro@uol.com.br \\ Universidade Federal de Lavras | Programa de Pós-Graduação em Administração \\ Lavras | Minas Gerais | Brasil \\ Rita de Cássia Arantes, Mestre \\ https://orcid.org/0000-0002-6980-5443 \\ ritadecassia.arantes@gmail.com \\ Universidade Federal de Lavras | Programa de Pós-Graduação em Administração \\ Lavras | Minas Gerais | Brasil \\ Luiz Guilherme Rodrigues Antunes, Mestre \\ https://orcid.org/0000-0003-2997-2949 \\ luguiantunes@yahoo.com.br \\ Faculdade São Lourenço | Setor de Administração, Ciências Contábeis e Recursos Humanos \\ Lavras | Minas Gerais | Brasil \\ Luiz Marcelo Antonialli, Doutor \\ https://orcid.org/0000-0003-1220-6164 \\ lmantonialli@gmail.com \\ Universidade Federal de Lavras | Programa de Pós-Graduação em Administração \\ Lavras | Minas Gerais | Brasil
}

Recebido em 05/dezembro/2018

Aprovado em 15/outubro/2019

Publicado em 02/janeiro/2020

Sistema de Avaliação: Double Blind Review

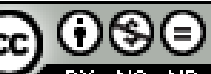

Esta obra está sob uma Licença Creative Commons Atribuição-Uso. 


\title{
RESUMO
}

O objetivo dessa pesquisa foi analisar o retorno para as startups, a partir da adoção de uma metodologia ativa, a Técnica Multidimensional de Ensino (TME), na opinião dos alunos que cursaram a disciplina de Empreendedorismo Tecnológico do Curso de Administração na UNIFEI. Para tanto, utilizou-se como método, o estudo de caso. Para coleta de dados, utilizou-se de duas fontes: documentos (45 relatórios entregues pelos alunos no período de 2012 a 2016) e questionários (122 respostas válidas, aplicados pela ferramenta Survey Monkey ${ }^{\circledR)}$. Quanto às análises dos documentos, utilizaram-se de análise de conteúdo por frequência e categorias. Para a análise dos questionários, utilizou-se de técnicas multivariadas: análise de cluster e análise discriminante (método Stepwise). Os resultados evidenciam que houveram implicações da TME para a sociedade (startups), sendo avaliadas como positivas para alunos. A TME também mostrou-se como uma metodologia pertinente para a formação do administrador, especificamente no contexto das startups, visto que proporcionou ao discente aprendizagem e troca de experiências situadas em um contexto. Foi evidenciado que com o amadurecimento da técnica ao passar dos anos, aumenta a aceitação dos alunos a metodologia, e isso é percebido pelos alunos que cursaram a disciplina nos últimos três anos com maior dedicação ao projeto.

Palavras-chave: Empreendedorismo Tecnológico. Metodologia Ativa. Técnica Multidimensional de Ensino (TME).

\begin{abstract}
The objective of this research was to analyze the return to startups based on the adoption of an active methodology, the Multidimensional Teaching Technique (MTT), in the opinion of the students who attended the course of Technological Entrepreneurship Course of Administration at UNIFEI. For that, the case study was used as method. For data collection, two sources were used: documents ( 45 reports delivered by students in the period from 2012 to 2016) and questionnaires (122 valid answers, applied by the Survey Monkey® tool). Regarding the analyzes of the documents, content analysis by frequency and categories was used. For the analysis of the questionnaires, we used multivariate techniques: cluster analysis and discriminant analysis (Stepwise method). The results evidenced that there were implications of MTT for the society (startups), being evaluated as positive for students. MTT also proved to be a relevant tool for administrator training, specifically in the context of startups, as it provided the learner with learning and exchange of experiences situated in a context. It was evidenced that with the maturation of the technique over the years, students' acceptance of the methodology increases, and this is perceived by the students who have studied the discipline in the last three years with greater dedication to the project.
\end{abstract}

Keywords: Technological Entrepreneurship. Active Methodology. Multidimensional Teaching Technique (MTT). 


\section{A TÉCNICA MULTIDIMENSIONAL DE ENSINO E OS BENEFÍCIOS PROPORCIONADOS ÀS

\section{INTRODUÇÃO}

Mediante as transformações da contemporaneidade, o contexto de atuação da Universidade, bem como seu entorno tem experimentando diversas alterações. Dentre as diversas mudanças enfrentadas por essas instituições, estão as transformações nas concepções de ensino-aprendizagem (FRANCISCO et al., 2017). As universidades podem ser consideradas atores centrais na sociedade, visto que atuam na formação de cidadãos e também promovem ambientes de inovação e empreendedorismo, proporcionando ativos que podem ser transferidos aos agentes sociais (GIMENEZ; BAMBINI; BONACELLI, 2016).

Nesse contexto de transformações, emerge um novo tipo de organização, ora denominadas de startups ora de empresas de base tecnológica (EBTs). Entre as características desse tipo de negócio está o uso intensivo de conhecimentos científicos e tecnológicos, e desse modo, a aproximação dessas empresas às universidades se torna fundamental. Nesse sentido, a universidade contribui desenvolvendo especialistas capacitados na área tecnológica para atuarem como mão de obra especializada e desenvolvedores de novas startups (BOLLINGER; HOPE; UTTERBACK, 1983; GUERRERO; URBANO, 2011; NACU; AVASILCÃI, 2014), propiciando desenvolvimento econômico.

Entretanto, essa relação ainda se restringe a conceitos de natureza técnica, sendo cada vez mais necessário o desenvolvimento de especialistas na área de gestão desses negócios. Tal argumentação pode ser justificada à medida que as EBTs morrem antes mesmo da sua consolidação devido a diversos problemas gerenciais (CHAVES; SILVA, 2004, ANDINO; FRACASSO, 2005, ENGELMAN; FRACASSO; BRASIL, 2011).

Assim, a função da universidade (principalmente as de produção de tecnologias) passa a ser de desempenhar suas atividades focada no desenvolvimento do corpo docente e discente, preparando-os para atender as necessidades desses negócios (SCHMITZ et al., 2016). Desta forma, tais problemas passam da arena das empresas para a sala de aula, sobretudo no campo da Administração. Nessa direção, o empreendedorismo tecnológico ganha destaque.

O empreendedorismo tecnológico pode ser caracterizado como um novo conceito empresarial em tecnologia, que envolve também a gestão de riscos (NACU; AVASILCÃI, 2014). No entanto, um dos problemas do empreendedorismo tecnológico é a dificuldade de se alinhar o ensino de matérias técnicas - inovação e tecnologia - com matérias de negócio business plan, mercado financeiro, estratégia e outros. (KELLEY; SINGER; ILERRINGTON, 2011). Uma possível alternativa é a utilização de metodologias ativas, que 


\section{A TÉCNICA MULTIDIMENSIONAL DE ENSINO E OS BENEFÍCIOS PROPORCIONADOS ÀS

são metodologias embasadas na pedagogia problematizadora empregadas nas soluções de problemas contextualizados (BERBEL, 2012, SOUZA; SHIGUTI; RISSOLI, 2013).

Entre as possibilidades de metodologias ativas, encontra-se a Técnica Multidimensional de Ensino (TME), que é inspirada na didática multidimensional, onde se busca integrar teoria, indivíduo e resultados para sociedade. Essa metodologia é formada por diversos atores além do discente e docente, que estão inseridos na sociedade e podem representar diferentes possibilidades de aprendizagem. Desse modo, a TME não se limita na difusão de conhecimento, mas sim no seu desenvolvimento, bem como no envolvimento do discente com um novo contexto para aprendizagem (FRANCO; PIMENTA, 2016).

Diante do exposto, essa abordagem nos direciona a seguinte reflexão: Como a TME, enquanto metodologia ativa de ensino pode gerar resultados concretos para startups?

Diante disso, o objetivo desse estudo é analisar o retorno da TME para as startups, a partir da opinião dos alunos que cursaram a disciplina de Empreendedorismo Tecnológico do Curso de Administração na Universidade Federal de Itajubá (UNIFEI) entre 2012 a 2016. Para isso, estabeleceu-se os seguintes objetivos específicos: (i) Avaliar a opinião dos alunos sobre o retorno à sociedade no momento da disciplina; e (ii) Avaliar a opinião dos alunos sobre o retorno à sociedade após terem cursado a disciplina. Para tanto, utilizou-se de análise de documentos e análise multivariada, com as técnicas de análise de cluster e discriminante.

Esse artigo está dividido em quatro seções além desta introdução. O referencial teórico aborda a universidade e o empreendedorismo tecnológico, e a metodologia ativa e TME. Na sequência têm-se os aspectos metodológicos. Apresenta-se a análise e discussão dos resultados e as considerações finais e limitações deste estudo.

\section{REFERENCIAL TEÓRICO}

\subsection{UNIVERSIDADE E O EMPREENDEDORISMO TECNOLÓGICO}

A sociedade do conhecimento caracterizada por fluxos dinâmicos e contínuos tem remodelado as concepções de universidade e provocado discussões acerca do seu papel para a sociedade (GUERRERO; URBANO, 2011). Para Etzkowitz e Klofsten (2005), a ênfase no conhecimento como fator-chave do desenvolvimento econômico e social, fez com as universidades, enquanto agente de criação e disseminação do conhecimento, assumissem uma nova função nas esferas sociais.

Nessa direção, para Schmitz et al. (2016), a universidade está sendo constantemente desafiada a se tornar, de fato, uma instituição social mais atuante. Na visão dos autores, este 


\section{A TÉCNICA MULTIDIMENSIONAL DE ENSINO E OS BENEFÍCIOS PROPORCIONADOS ÀS

novo posicionamento da universidade tem sido tratado dentro das perspectivas do empreendedorismo e da inovação. A razão para tal consiste no fato de que, quando as universidades incentivam e promovem o empreendedorismo e a inovação, elas estarão mais atentas aos anseios da sociedade, podendo contribuir de forma mais efetiva para o desenvolvimento econômico e social da comunidade que estão inseridas.

Uma forma efetiva que a universidade dispõe para contribuir com o desenvolvimento do seu entorno é a disseminação do conhecimento ali construído, ou seja, expandindo as descobertas para além de seus muros e colocando-as a serviço da comunidade; para que os conhecimentos gerados possam ser aplicados e utilizados na geração de renda e melhorias das condições sociais (SCHMITZ et al., 2016).

Outra forma de contribuição para desenvolvimento da comunidade, na visão de Santos e Cunha (2004) e Freire et al. (2014) está na promoção de empresas de base tecnológica (EBT). Nesse sentido, o conceito de empreendedorismo tecnológico pode ser denominado como uma nova concepção empresarial em tecnologia, envolvendo também a gestão de riscos (NACU; AVASILCÃI, 2014). Conforme Menck e Oliveira Filho (2009) esse tipo de empreendedorismo é composto por um tipo peculiar de empresa: a startup (OAKEY, 2012).

As startups apresentam-se como peça chave para o cenário global. Entretanto, cabe destacar, que muitos são os desafios para o sucesso dessas empresas, devido às suas origens e seu tamanho. Com o intuito de minimizar esses obstáculos, vários estímulos são direcionados para o desenvolvimento desses empreendimentos, como os investimentos nos grupos de alta tecnologia no Vale do Silício (OAKEY, 2012; PORTO, 2013).

No Brasil o movimento de Incubadoras de EBTs e Parques Científicos-Tecnológicos reforçaram o desenvolvimento do empreendedorismo tecnológico (PORTO, 2013). Além desses programas, destaca-se a fundação, em 2011, da Associação Brasileira de Startups (ABStartups) com o propósito de incentivar um ecossistema nacional de Startups internacionalmente reconhecido (GODOI-DE-SOUSA; LOPES, 2016). Essas iniciativas estão atreladas às universidades, que passaram a incentivar o desenvolvimento de pesquisas inovadoras e de alta tecnologia, sendo muitas dessas iniciativas as parcerias ou criação de incubadoras de EBTs (PORTO, 2013), desenvolvimento de spin-offs (ETZKOWITZ; LEYDESDORFF, 2000), alavancagem do empreendedorismo acadêmico, transferência de tecnologias (HAASE; ARAÚJO; DIAS, 2005) e formação especializada de mão de obra (ROSENBERG; NELSON, 1994). 


\section{A TÉCNICA MULTIDIMENSIONAL DE ENSINO E OS BENEFÍCIOS PROPORCIONADOS ÀS

Nesse sentido, Menck e Oliveira Filho (2009) afirmam que embora a utilização de incubadoras de empresas esteja cada vez mais presente nas universidades ou em seu entorno, esses empreendimentos ainda encontram vários desafios para atingir seus objetivos. Dessa maneira, é preciso que pesquisadores, gestores e instituições tomem consciência dos desafios desses empreendimentos, e reforcem essas iniciativas.

Por fim, cabe destacar que as universidades não devem se isolar em "torres de marfim" (MOWERY; SAMPAT, 2004), ao contrário, devem estar inseridas aos problemas da sociedade. Para isso, se faz importante aplicar os conceitos teóricos, por meio da ação docente, de modo a fazer com que o aluno reflita e tome consciência de suas ações na sociedade (aprendizagem transformadora), ao invés de meramente reaplicar tais modos de fazer (FRANCO; PIMENTA, 2016).

\subsection{AS METODOLOGIAS ATIVAS E A TÉCNICA MULTIDIMENSIONAL DE ENSINO}

As metodologias ativas surgem com uma alternativa para remodelar o processo de ensino-aprendizagem tradicional. As metodologias ativas podem ser compreendidas como ferramentas que visam o desenvolvimento crítico de futuros profissionais em diversas áreas. Elas são capazes de fornecer ao educando mais autonomia no processo de aprendizagem, além de possibilitar o desenvolvimento de habilidades interpessoais, que podem ser consideradas essenciais para a prática social, bem como para o contexto profissional do estudante (BORGES; ALENCAR, 2014).

As metodologias ativas consideram no processo de ensino-aprendizagem a imersão do discente em experiências reais ou simuladas que exijam a solução de problemas condizentes com a prática social da área em estudo (SOUZA; SHIGUTI; RISSOLI, 2013). Desta forma, a metodologia ativa considera o aluno o ator principal no processo de ensino aprendizagem (ARAÚJO, 2015). Snyder (2003) complementa que o aluno tem um papel participativo, pois a metodologia ativa proporciona diferentes maneiras de desafiar os alunos, estimulá-los a entender os conceitos teóricos e buscar informação (HARTZ; SCHLATTER, 2016).

Snyder (2003) e Kitchens, Means e Tan (2018) destacam que entre as características da aprendizagem ativa estão: (i) maior ênfase no desenvolvimento de habilidades de pensamento analítico e crítico; (ii) alunos fazem algo diferente e não ouvem passivamente; (iii) há envolvimento dos alunos em alguma atividade; (iv) há foco na exploração de atitudes e valores; e (v) as situações proporcionam maior absorção do conhecimento. 


\section{A TÉCNICA MULTIDIMENSIONAL DE ENSINO E OS BENEFÍCIOS PROPORCIONADOS ÀS

Há diversas metodologias ativas, entre elas: Aprendizado Baseado em Problemas, Estudos de Casos, Debates e Jogos (SNYDER, 2003; HARTZ; SCHLATTER, 2016; KITCHENS; MEANS; TAN, 2018) e a Técnica Multidimensional de Ensino. Franco e Pimenta (2016) apontam que a multidimensionalidade considera a totalidade no ensino, ou seja, cria-se novos significados para o processo de aprendizagem do aluno, ressaltando tanto o desenvolvimento cognitivo e comportamental do indivíduo quanto as situações que emergem para que o aprendizado seja significativo.

De forma complementar, Mena (2017) caracteriza na multidimensionalidade da didática um processo de desenvolvimento de habilidades escritas e orais, favorecendo possibilidades de integração social. Pasquarelli e Oliveira (2017) reforçam que a didática multidimensional propicia técnicas e estratégias aos alunos para um processo de ensinoaprendizagem que prioriza a prática cidadã, para intervir e participar na sociedade.

Franco (2013) e Franco e Pimenta (2016) reforçam que a didática multidimensional objetiva a produção de atividade intelectual para o aluno, considerando os contextos nos quais os processos de ensinar e aprender estão inseridos. O ensino exige uma consonância nos atos e nas formas de ensinar. A ação de ensinar é uma prática social representada por diversas interações entre docentes, alunos, instituição e sociedade, inseridas em contextos socioculturais e históricos.

O processo de ensino-aprendizagem é percebido quando há uma articulação entre as dimensões teórica, humana e político-social (CANDAU, 2012). É necessário estabelecer um processo que possibilite ao aluno o aprendizado de novos conceitos (teoria), desenvolvimento de novas habilidades pessoais (indivíduo), além de envolvimento com o contexto no qual está inserido (sociedade). Dessa maneira, a TME se demonstra composta por essas três dimensões: (i) Teoria, (ii) Indivíduo e (iii) Sociedade.

Na dimensão teórica ou técnica, Rangel (2010) e Gomes et al. (2015) reforçam que os principais objetivos para um processo de aprendizagem é o conteúdo aprendido e compreendido pelo discente através do professor. Esta vertente considera como o conteúdo é organizado para proporcionar o acesso ao conhecimento (RANGEL, 2010). Em outras palavras, considera-se nesse processo: (i) o objetivo teórico que será trabalhado, (ii) a seleção do conteúdo que será estudado, e (3) a forma de avaliação mais adequada. Em complemento, Candau (2012) adiciona que o conteúdo a ser estudado e a definição de qual método deve ser utilizado, alcança mais significado se for abordado em uma situação contextualizada. 


\section{A TÉCNICA MULTIDIMENSIONAL DE ENSINO E OS BENEFÍCIOS PROPORCIONADOS ÀS

Na dimensão humana ou indivíduo, Lemos et al. (2011) adicionam que a educação do administrador precisa concentrar-se no desenvolvimento de competências e de habilidades para ocupações em instituições privadas, públicas ou sem fins lucrativos. Desta forma, Candau (2012) e Hummel, Pifaff e Rost (2016) reforçam que o desenvolvimento de habilidades pessoais, éticas, comportamentais e interpessoais, bem como a melhoria de atitudes, como: empatia, valor, proatividade são parte essencial da dimensão humana do processo de aprender.

Por fim, a dimensão sociedade ou político-social relaciona o aluno em contato direto com uma instituição, que pode ser representada por organizações públicas, privadas ou instituições sem fins lucrativos. Essa dimensão vai além do limite de sala de aula e ocorre numa cultura específica, trata com fatos concretos e pessoas inseridas no contexto em que vivem (CANDAU, 2012; FRANCO; PIMENTA, 2016). A conexão com um mundo real proporciona ao discente uma reflexão de suas experiências e envolvimento com o objeto pesquisado. O discente tem autonomia para desenvolver o seu papel no contexto que está inserido (GOMES et al., 2015).

Neste sentido, faz-se necessário entender a aplicação da TME enquanto uma técnica de ensino e verificar se a dimensão sociedade realmente pode se beneficiar em um processo de ensino-aprendizagem dos alunos.

\section{MÉTODOS E PROCEDIMENTOS}

O método de pesquisa utilizado foi o estudo de caso, caracterizado por Yin (2001) como um tipo de análise crítica e profunda de um fenômeno de investigação. Quanto a sua natureza, utilizou-se de métodos mistos, que combina abordagens quantitativas e qualitativas, o que proporciona uma melhor compreensão dos problemas de pesquisa do que abordagens isoladas (CRESWELL; CLARK, 2006). Com o propósito de investigar um caso representativo, optou-se por realizar um estudo da disciplina de Empreendedorismo Tecnológico do curso de Administração de Empresas da UNIFEI. Nessa disciplina, a técnica é aplicada desde 2012, envolvendo um total de 167 alunos e 23 startups.

Uma das atividades da disciplina considera o desenvolvimento de um Projeto de Empreendedorismo Tecnológico, chamado Caçadores de Anjos, no qual considera-se alunos, docente, investidores e startups como parte do processo de ensino-aprendizado. Tal projeto foca a inserção dos alunos no ambiente de Empreendedorismo Tecnológico por meio da 


\section{A TÉCNICA MULTIDIMENSIONAL DE ENSINO E OS BENEFÍCIOS PROPORCIONADOS ÀS

execução de um projeto para uma EBT. Para o desenvolvimento desse projeto, as empresas beneficiadas são escolhidas pelo docente. Os alunos a conhecem ao longo do semestre, desenvolvem instrumentos para contatar investidores anjos, buscam investidores interessados no ramo de atuação da empresa e intermediam as reuniões iniciais entre eles. Além da inserção dos alunos no ambiente de aprendizagem, o projeto permite a visualização dos problemas de gestão e melhoria do modelo de negócios pelos alunos.

Ao que se refere a forma de coleta de dados, utilizou-se de duas fontes primárias: documentos e questionários. Os documentos coletados são representados pelos 45 relatórios finais entregues pelos alunos matriculados na disciplina no período de 2012 a 2016. Foram coletadas as informações sobre os benefícios proporcionados às empresas na opinião dos alunos desenvolvedores do projeto.

Em relação aos questionários, foi utilizado um questionário eletrônico aplicado por meio da ferramenta Survey Monkey®. O propósito do instrumento foi analisar a opinião dos alunos sobre o retorno às startups após terem concluído a disciplina. As startups são a representação da dimensão sociedade da TME.

Quanto ao questionário, foi constituído por uma escala de concordância de cinco pontos, com a seguinte legenda: (1) discorda totalmente, (2) discorda parcialmente, (3) indiferente, (4) concorda parcialmente e (5) concorda totalmente. Ademais, o instrumento foi dividido em cinco grandes blocos, a saber: informações gerais e demográficas; teoria; indivíduo; sociedade; e avaliação da TME. Além disso, foi realizado um pré-teste na primeira quinzena de junho de 2017, com taxa de retorno de 75\% (15 questionários). O Quadro 01 apresenta as variáveis que compõe a dimensão da sociedade, bem como as variáveis da dimensão "Avaliação da TME”, utilizadas na pesquisa.

Quadro 01 Variáveis que compõe a dimensão "Sociedade" e "Avaliação da TME"

\begin{tabular}{|l|l|}
\hline \multicolumn{1}{|c|}{ Variáveis que compõe o questionário } & Dimensões \\
\hline As atividades da empresa e sua atuação no mercado ficaram claras para o grupo. & \\
\hline $\begin{array}{l}\text { O retorno das solicitações de informações feitas à empresa ocorria em tempo suficiente } \\
\text { para a execução do trabalho. }\end{array}$ & \\
\hline $\begin{array}{l}\text { Houve sigilo, por parte dos alunos, em relação as informações confidenciais obtidas das } \\
\text { empresas. }\end{array}$ & \multirow{2}{*}{ Sociedade } \\
\cline { 1 - 1 } $\begin{array}{l}\text { As agendas entre os empresários e investidores anjo foram conciliáveis para as entrevistas } \\
\text { marcadas pelos alunos. }\end{array}$ & \\
\hline Os dados sobre a empresa foram facilmente acessados. & \\
\hline O Canvas elaborado pelo grupo foi utilizado pela empresa. & \\
\hline O Pitch elaborado foi utilizado pela empresa. & \\
\hline $\begin{array}{l}\text { Os alunos proporcionaram outras entregas para a empresa (como: folders, revisão do } \\
\text { sumário executivo) que ajudaram na promoção do negócio. }\end{array}$ & \\
\hline
\end{tabular}




\section{A TÉCNICA MULTIDIMENSIONAL DE ENSINO E OS BENEFÍCIOS PROPORCIONADOS ÀS STARTUPS LOCAIS: UMA PERSPECTIVA DOS ALUNOS DOI: http://dx.doi.org/10.5007/1983-4535.2020v13n1p70}

\begin{tabular}{|c|c|}
\hline Variáveis que compõe o questionário & Dimensões \\
\hline $\begin{array}{l}\text { A empresa melhorou seu modelo ou plano de negócios a partir dos contatos } \\
\text { proporcionados pelos alunos. }\end{array}$ & \\
\hline $\begin{array}{l}\text { O grupo buscou contatos além dos investidores anjos para auxiliar nos negócios da } \\
\text { empresa. }\end{array}$ & \\
\hline O grupo aumentou a divulgação da empresa com os contatos proporcionados. & \\
\hline O grupo proporcionou contatos com investidores anjos ou grupos de investidores anjo. & \\
\hline $\begin{array}{l}\text { As conversas entre empresários e investidores ajudaram a empresa a ter novas percepções } \\
\text { do seu negócio. }\end{array}$ & \\
\hline $\begin{array}{l}\text { Os contatos com os investidores anjos proporcionados pelo grupo ajudaram no networking } \\
\text { da empresa. }\end{array}$ & \\
\hline $\begin{array}{l}\text { Os investidores anjos intermediados pelo grupo ajudaram a empresa com mentorias sobre } \\
\text { o foco do negócio. }\end{array}$ & \\
\hline $\begin{array}{l}\text { Nas conversas entre investidores e empresários foram identificadas as possibilidades de } \\
\text { projetos conjuntos entre eles. }\end{array}$ & \\
\hline O grupo cadastrou a empresa em bases de investimento anjo. & \\
\hline $\begin{array}{l}\text { Identifica-se uma relação teórica entre o conteúdo e as atividades desenvolvidas no } \\
\text { Projeto "Caçadores de Anjos". }\end{array}$ & \multirow{5}{*}{$\begin{array}{l}\text { Avaliação da } \\
\text { TME }\end{array}$} \\
\hline $\begin{array}{l}\text { São criadas situações de aprendizado fora do contexto de sala de aula, onde o aluno pode } \\
\text { desenvolver habilidades pessoais. }\end{array}$ & \\
\hline $\begin{array}{l}\text { A troca de experiência entre alunos, empresários e investidores "anjos" proporciona } \\
\text { benefícios para as partes envolvidas }\end{array}$ & \\
\hline O contato com empresários e investidores auxilia no processo de aprendizado. & \\
\hline $\begin{array}{l}\text { A Técnica Multidimensional de Ensino pode ser uma alternativa ativa para o aprendizado } \\
\text { dos alunos em Administração. }\end{array}$ & \\
\hline
\end{tabular}

Fonte: Elaborado pelos autores

No que tange as análises, para a análise dos documentos, utilizou-se de análise de conteúdo por frequência e por categorias. A análise de conteúdo por frequência consiste na identificação das respostas dos entrevistados e agrupamentos conforme cada pergunta, utilizando a estatística descritiva (BARDIN, 2016). Já a análise temática, ou de categorias, busca-se descobrir os núcleos de sentidos que compõe uma comunicação sobre determinado tema presente nos discursos dos respondentes (MINAYO, 2000).

Para a análise dos questionários, utilizou-se de técnicas multivariadas e as escalas ordinais foram assumidas como intervalares. Foram enviados 167 questionários a população, durante os meses de junho a julho de 2017, e obteve-se $73,05 \%$ de retorno (122 questionários). Assim, a amostra foi considerada satisfatória. Segundo Hair Junior et al. (2005) o tamanho da amostra para análise não deve ser menor que 50.

Para as análises multivariadas, utilizou-se o software SPSS (Statistical Package for the Social Sciences). Primeiramente, as variáveis que compõe as dimensões "Sociedade" e "Avaliação da TME" foram submetidas ao teste de confiabilidade de Alfa de Cronbach (HAIR JUNIOR et al., 2005). Após a constatação de confiabilidade dos dados, foi realizada a análise de aglomerados (ou clusters) para as variáveis preditoras do construto sociedade. Por fim, procedeu-se a análise discriminante, com o intuito de caracterizar e analisar de forma 


\section{A TÉCNICA MULTIDIMENSIONAL DE ENSINO E OS BENEFÍCIOS PROPORCIONADOS ÀS

específica os clusters extraídos na etapa anterior. Foi escolhido o Método Stepwise (por etapas), por estimar as funções discriminante, do qual as variáveis independentes entram sequencialmente de acordo com o poder discriminatório que elas acrescentam a precisão no grupo (HAIR JUNIOR et al., 2005).

\section{ANÁLISE DOS RESULTADOS E DISCUSSÕES}

Os resultados e discussões são apresentados em três etapas: (i) Opinião dos Alunos sobre os Benefícios à sociedade no momento da disciplina; (ii) Opinião dos Alunos sobre os Benefícios à sociedade após terem cursado a disciplina; e (iii) síntese e discussão.

\subsection{OPINIÃO DOS ALUNOS SOBRE OS BENEFÍCIOS À SOCIEDADE NO MOMENTO DA DISCIPLINA}

Com o intuito de corroborar com a investigação sobre os benefícios da TME para a sociedade, representada pelas startups participantes do projeto, foi analisado os 45 relatórios finais entregues pelos alunos da disciplina. Os documentos foram analisados por meio de análise de conteúdo por frequência e temática.

A estrutura do relatório continha um resumo da startup participante, a estratégia e execução do projeto, o aprendizado teórico dos alunos, as oportunidades de desenvolvimento pessoal e os benefícios gerados para a empresa. Nesta etapa, foram analisados o item de benefícios gerados dos 45 relatórios, distribuídos entre alunos participantes da disciplina de 2012 a 2016.

A Tabela 1 resume os resultados predominantes durante os 5 anos de aplicação da TME, na dimensão sociedade. No que tange a forma de apresentação dos resultados, apontase inicialmente os resultados a cada ano, e posteriormente um resumo geral.

Tabela 1 Resultados predominantes para Sociedade

\begin{tabular}{c|l}
\hline $\begin{array}{c}\text { Ano/ } \\
\text { Dimensão }\end{array}$ & \multicolumn{1}{c}{ Sociedade (startups) } \\
\hline $\mathbf{2 0 1 2}$ & - Melhoria do Canvas ou Plano de Negócios e Divulgação da Empresa (44,4\%). \\
\hline $\mathbf{2 0 1 3}$ & $\begin{array}{l}\text { - Elaboração do Canvas e o contato com diversos investidores com }(90 \%) ; \\
\text { - Os pitches elaborados (70\%). }\end{array}$ \\
\hline $\mathbf{2 0 1 4}$ & - Elaboração do Canvas, pitch e o contato com diversos investidores (100\%). \\
\hline $\mathbf{2 0 1 5}$ & - Elaboração do Canvas, pitch, mentoria dos investidores (71,4\%). \\
\hline $\mathbf{2 0 1 6}$ & $\begin{array}{l}\text { - Contato com diversos investidores (100\%); } \\
\text { - Elaboração do pitch e do Canvas (66,7\%). }\end{array}$ \\
\hline \multirow{2}{*}{ Geral } & $\begin{array}{l}\text { - Elaboração do Canvas (75,5\%); } \\
\text { - Contato com diversos investidores anjos }(68,8 \%) ; \\
\text { - Elaboração do pitch }(66,7 \%) .\end{array}$ \\
\hline
\end{tabular}

Fonte: Dados da Pesquisa 


\section{A TÉCNICA MULTIDIMENSIONAL DE ENSINO E OS BENEFÍCIOS PROPORCIONADOS ÀS

Nos resultados proporcionados pela empresa a partir da opinião dos alunos enquanto cursavam a disciplina, percebe-se maior evidência em relação aos instrumentos gerenciais elaborados pelos alunos e utilizados pela empresa, além do contato com diversos investidores, que é citado nos anos de 2013, 2014 e 2016. No resultado final a elaboração e revisão do Canvas é o resultado mais expressivo, seguido pelo contato com diversos investidores anjos, que apoiam com mentorias gerenciais para melhorias no negócio.

De forma complementar, são apresentados alguns trechos retirados dos relatórios que refletem a contribuição dos alunos para as startups:

Fizemos uma consultoria para a área comercial da empresa, desenvolvemos o pitch e o Canvas, e vários investidores foram contatados. Os contatos com os investidores anjos pode aumentar a rede de relacionamento da startup, além de aumentar a visibilidade do negócio (RELATÓRIO 7, 2013).

Através de nosso intermédio, foi feito convite para apresentação da startup no Núcleo Anjos de Minas, foi feito contato com um fundo de Venture Capital, a empresa foi cadastrada em diversas plataformas de investimento anjo, auxiliamos a empresa nos testes da plataforma. Criamos um plano de comunicação para a empresa com sumário resumido, pitches e vídeo institucional. Os materiais que desenvolvemos ajudaram a empresa a se classificar em um programa de aceleração estadual (RELATÓRIO 3, 2014).

(...) Em síntese, os maiores resultados e benefícios que acreditamos ter agregado à empresa foram: (1) contato com fundo de Venture Capital: (2) legado de pitch, deck, Canvas, portfólio de notícias e folder explicativo, o que até então a empresa não possuía; (3) inscrições em plataformas de investimento como a X e Y, bem como nas aceleradoras como a $\mathrm{M} \mathrm{e} \mathrm{N}$; (4) divulgação da startup por meio de mídias sociais, já que o site ainda não está pronto; (5) oportunidade na sala do Empreendedor; (6) Agenda de eventos e prazo de inscrição nas aceleradoras. Indiretamente também auxiliamos os empresários a terem mais clareza e organização nas informações sobre a empresa para lançá-la ao mercado, como oportunidade, solução, diferenciais, etc., tendo em vista que para nos fornecer tais informações, eles tiveram de se reunir e discuti-las. Isso culminou na adoção de um foco maior em indústrias de pequeno e médio porte como público-alvo inicial e na meta de conseguir um investimento de $\mathrm{R} \$ 250.000,00$ para alavancagem da empresa e produção de um lote de 100 unidades" (RELATÓRIO 6, 2015).

Os relatos complementam os resultados obtidos na análise de conteúdo por frequência e ressaltam a relevância do projeto para uma reflexão de empresa, de aspectos comerciais e mercadológicos, além de possibilidades concretas de investimento às startups participantes do projeto. 


\section{A TÉCNICA MULTIDIMENSIONAL DE ENSINO E OS BENEFÍCIOS PROPORCIONADOS ÀS

\subsection{OPINIÃO DOS ALUNOS SOBRE OS BENEFÍCIOS À SOCIEDADE APÓS TEREM CURSADO A DISCIPLINA}

Após terem concluído a disciplina e já estarem em outros períodos do curso. Os alunos responderam um questionário sobre sua opinião em relação aos benefícios proporcionados à sociedade. Para análise, procedeu-se de análises multivariadas.

Inicialmente, foi analisado o Alfa de Cronbach dos constructos do estudo (sociedade e avaliação da TME). A dimensão sociedade apresentou um alfa de 0,866. Já na dimensão de avaliação da TME, obteve-se o resultado de 0,999. Nesta direção, observa-se que os constructos e variáveis apresentam-se confiáveis a partir dos parâmetros propostos por Hair Junior et al. (2005). Na concepção dos autores o valor mínimo requerido deve estar acima de 0,60, o valor obtido evidencia que os dados desta análise são altamente confiáveis.

Na sequência, procedeu-se a análise de cluster, com o intuito de identificar o perfil dos alunos quanto às implicações da TME para a sociedade. Assim, os resultados apontam dois clusters distintos: i) um cluster formado por 95 respondentes (78\%); e ii) um cluster constituído de 27 respondentes (22\%).

A fim de explorar o perfil dos dois grupos, todas as variáveis de caracterização dos respondentes foram submetidas ao teste Qui-Quadrado, considerando um nível de significância de 5\% (HAIR JUNIOR et al., 2005). A Tabela 2 evidencia as relações entre os grupos extraídos e as variáveis significativas, sendo: (i) o gênero do respondente ( $p$-value = 0,014); (ii) o ano em que o respondente cursou a disciplina ( $p$-value $=0,017$ ); e (iii) a dedicação quinzenal dos alunos $(p$-value $=0,023)$. Os valores indicam que há diferenças entre os grupos nessas variáveis com nível de significância menor que 5\%. Assim, os agrupamentos são predominantes constituídos por:

Tabela 2 Caracterização dos Grupos

\begin{tabular}{|c|c|c|}
\hline & Cluster 1 & Cluster 2 \\
\hline Gênero & Sexo feminino $(63,1 \%)$ & Sexo masculino $(62,9 \%)$ \\
\hline Ano que cursou a disciplina & Entre os anos de 2014 a 2016 & Anos de 2012 e 2013 \\
\hline Dedicação quinzenal dos alunos & Acima de 4 horas $(36,8 \%)$ & Entre 2 a 3 horas $(40,7 \%)$ \\
\hline
\end{tabular}

Fonte: Dados da pesquisa

Tendo em vista os perfis apresentados, após a análise de cluster, realizou-se uma análise discriminante, com o intuito de identificar a relação entre as variáveis analisadas e os clusters. Nesse caso, foram analisadas as variáveis de avaliação da TME e as variáveis da 


\section{A TÉCNICA MULTIDIMENSIONAL DE ENSINO E OS BENEFÍCIOS PROPORCIONADOS ÀS

dimensão sociedade. Além disso, assumiu-se como hipótese nula que não haveria diferenças entre os clusters. Dessa forma, as variáveis foram submetidas ao teste de Lambda de Wilks, que evidenciou a rejeição da hipótese de nulidade, a um nível de significância de $1 \%$, indicando, desse modo, que há diferenças entre os clusters.

O Método Stepwise foi utilizado para a obtenção das variáveis discriminantes. Como resultados, as variáveis discriminadas na dimensão sociedade foram: (i) conversas entre empresas e investidores, proporcionadas pelo grupo, ajudaram a empresa; (ii) foram criadas situações de aprendizado fora da sala de aula; (iii) a empresa melhorou seu modelo de negócio ou plano de negócio; (iv) troca de experiências entre alunos, empresas e investidores anjo proporcionaram benefícios; (v) os investidores anjos, por intermédio do grupo, auxiliaram as empresas com mentoria sobre o negócio; e (vi) o grupo buscou contatos além dos investidores para auxiliar a empresa.

A função discriminante das variáveis da dimensão sociedade apresentaram correlação canônica de 0,674. Ademais, 99,2\% dos respondentes apresentaram as mesmas características do seu respectivo cluster, indicando que as variáveis foram capazes de discriminar os clusters.

A partir das variáveis discriminantes, a Tabela 3 evidencia a relação entre os clusters e as variáveis discriminantes.

Tabela 3 Relação dos respondentes dos Clusters com as variáveis discriminatórias

\begin{tabular}{l|c|c}
\hline & Cluster 1 & Cluster 2 \\
\hline $\begin{array}{l}\text { Conversas entre empresas e } \\
\text { investidores proporcionadas pelos } \\
\text { alunos ajudaram a empresa }\end{array}$ & $\begin{array}{c}77,9 \% \text { concordam parcial ou } \\
\text { totalmente. }\end{array}$ & $74 \%$ não concordam. \\
\hline $\begin{array}{l}\text { Foram criadas situações de } \\
\text { aprendizado fora da sala de aula }\end{array}$ & $\begin{array}{c}93,7 \% \text { concordam parcial ou } \\
\text { totalmente. }\end{array}$ & $\begin{array}{c}48,1 \% \text { não concordam ou são } \\
\text { indiferentes }\end{array}$ \\
\hline $\begin{array}{l}\text { A empresa melhorou seu modelo } \\
\text { de negócio ou plano de negócio }\end{array}$ & $\begin{array}{c}63,2 \% \text { concordam parcial ou } \\
\text { totalmente, sendo 30,5\% foram } \\
\text { indiferentes. }\end{array}$ & $\begin{array}{c}66,6 \% \text { não concordam, sendo } \\
29,6 \% \text { indiferentes. }\end{array}$ \\
\hline $\begin{array}{l}\text { Troca de experiências entre alunos, } \\
\text { empresas e investidores anjo } \\
\text { proporcionaram benefícios }\end{array}$ & $\begin{array}{c}94,8 \% \text { concordam parcial ou } \\
\text { totalmente. }\end{array}$ & $\begin{array}{c}62,9 \% \text { não concordam ou são } \\
\text { indiferentes. }\end{array}$ \\
\hline $\begin{array}{l}\text { Os investidores anjos, por } \\
\text { intermédio do grupo, auxiliaram as } \\
\text { empresas com mentoria sobre o } \\
\text { negócio }\end{array}$ & $\begin{array}{c}68,4 \% \text { concordam parcial ou } \\
\text { totalmente. }\end{array}$ & $\begin{array}{c}100 \% \text { não concordam ou são } \\
\text { indiferentes. }\end{array}$ \\
\hline $\begin{array}{l}\text { O grupo buscou contatos além dos } \\
\text { investidores para auxiliar a } \\
\text { empresa }\end{array}$ & $\begin{array}{c}83,1 \% \text { concordam parcial ou } \\
\text { totalmente. }\end{array}$ & $\begin{array}{c}44,4 \% \text { não concordam ou são } \\
\text { indiferentes. }\end{array}$ \\
\hline
\end{tabular}

Fonte: Dados da pesquisa 


\section{A TÉCNICA MULTIDIMENSIONAL DE ENSINO E OS BENEFÍCIOS PROPORCIONADOS ÀS

Desse modo, considerando os resultados apresentados, o Cluster 1 foi denominado “Concordantes” e o Cluster 2 "Discordantes” às implicações da TME para a sociedade.

Os "Concordantes" são constituídos, pela maioria, de respondentes do sexo feminino, que cursaram a disciplina entre os anos de 2014 a 2016 e que se dedicaram mais de quatro horas a cada quinze dias no projeto. Para esse grupo, o relacionamento entre empresas e investidores anjo é importante, dado que a troca de experiências entre eles pode proporcionar vários benefícios. Além disso, o grupo valoriza a mentoria dos investidores anjos para as empresas, mas concorda quanto a relevância da busca externa de informações para auxiliar a empresa e seu negócio. Ademais, o grupo acredita que o projeto proporcionou aprendizado e experiência fora da sala de aula.

Já os "Discordantes" são formados predominantemente, por respondentes do sexo masculino, que possivelmente cursaram a disciplina entre os anos de 2012 e 2013, e se dedicaram entre duas a três horas quinzenalmente para a execução do projeto. Esse grupo, não acredita que a mentoria oferecida pelos investidores anjo e nem o relacionamento com o investidor, contribuíram para o negócio da empresa. Contudo, somente uma parte do grupo, buscou contatos externos, a fim de auxiliar a empresa. Ademais, para parte do grupo, o projeto proporcionou aprendizado e experiência fora da sala de aula.

\subsection{DISCUSSÕES}

\subsubsection{Universidade e sociedade no contexto do empreendedorismo tecnológico}

Franco e Pimenta (2016) e Sobrinho (2015) apontam que a universidade precisa estar imersa aos problemas da sociedade, assumindo sua função social no desenvolvimento dos indivíduos. Uma forma de evidenciar essa função social é por meio da ação de ensinar, tornando os alunos conscientes de suas ações. Candau (2012) reforça que é necessário situar o ensino-aprendizagem no contexto político-social para que o aprendizado tenha mais significado.

Cabe destacar que, a experiência, por si só, pode ser considerada um gatilho ou uma forma de aprendizagem, que quando compartilhada e refletida, é capaz de promover novas concepções e avanços, ajudando aos envolvidos em um processo de reelaboração de saberes (ANDRADE; OLAVE, 2015). Logo, o aprendizado resultante desse projeto "Caçadores de Anjos" é capaz de proporcionar benefícios às empresas, alunos e investidores anjo, no qual há aplicação do conhecimento técnico visto em sala de aula pelos alunos, bem como proporciona 


\section{A TÉCNICA MULTIDIMENSIONAL DE ENSINO E OS BENEFÍCIOS PROPORCIONADOS ÀS

o desenvolvimento de habilidades pelos mesmo, por meio de um processo reflexivo e crítico, em um contexto situado.

Os resultados da análise de cluster e da análise discriminante evidenciaram dois grupos distintos. Observa-se que o Grupo 1, denominado "Concordantes" é anuente às implicações da técnica para a sociedade. Os respondentes desse grupo avaliaram positivamente a troca de experiência e o relacionamento entre startups, alunos e investidores anjo. Além disso, acreditam que o projeto contribuiu para o desenvolvimento de técnicas e instrumentos gerenciais, promovendo dessa forma um diálogo entre universidade e sociedade, e consideram que houve aprendizado fora da sala de aula. Isso reflete o legítimo papel da universidade, e especificamente do professor, de ampliar as possibilidades de aprendizado do aluno, fornecendo meios para que todo conteúdo seja situado e faça sentido para o mesmo (MOREIRA, 2010).

Já o grupo "Discordante" não percebeu os benefícios advindos do relacionamento e da troca de experiências. $\mathrm{O}$ grupo também se mostrou indiferente às aplicações das ferramentas gerenciais no projeto. Como possíveis justificativas para o surgimento desse grupo, tem-se que os mesmos podem não ter se adaptado a estratégia de ensino, ou não tiveram interesse suficiente na temática da disciplina.

Mesmo perante esse aspecto, Berbel (2012) afirma ser fundamental criar um ambiente de aprendizado para o aluno. Portanto, é preciso ouvir os alunos, valorizar suas ideias e opiniões, responder aos questionamentos e encorajá-los, com o intuito de motivá-los para a construção do próprio conhecimento. Desse modo, o estudante será capaz não só de aprender a aprender, mas, de fato, refletir sua própria ação (DIESEL; BALDEZ; MARTINS, 2017). Entretanto, é importante salientar que, o grupo "Discordante" também concorda quanto a geração de aprendizado fora da sala de aula, sendo que pode-se observar que $89,3 \%$ dos alunos envolvidos no projeto consideram a TME efetiva no relacionamento com a sociedade.

De modo geral, é possível afirmar que o processo de ensino-aprendizagem, com a utilização da TME, configura-se em uma atividade ativa, situada e crítica. Em outras palavras, se torna ativa, uma vez que coloca o aluno como centro do seu próprio processo de aprendizagem, respeitando a própria dignidade do sujeito (aluno) e sua história, bem como o atribui autonomia e responsabilidade, devido ao projeto que o discente está inserido. Tais aspectos são preconizados por Mitre et al. (2008), Berbel (2012) e Araújo (2015). Também se torna situada, visto que o contexto fora da sala de aula envolve mais do que teoria e os alunos 


\section{A TÉCNICA MULTIDIMENSIONAL DE ENSINO E OS BENEFÍCIOS PROPORCIONADOS ÀS

podem aprender com as demandas da sociedade, sobre a cultura do local onde estão inseridos, e pelas práticas de negócio, conforme apontam Cunha (2012), Jackson et al. (2017) e Jones (2014). E, por último, crítica, visto que pela prática contextualizada (problemas reais), o aluno passa de mero receptor de conhecimento, passivo em sala de aula, e se transforma em agente transformador, capaz de desenvolver raciocínio lógico, analítico e crítico as situações, conteúdos e problemas do dia-a-dia do empreendedor, afim de cumprir objetivos estabelecidos, nesse caso a aproximação da startup aos investidores anjos. Tal aspecto é abordado por Berbel (2012) e Souza, Shiguti e Rissoli (2013).

\subsubsection{Benefícios às startups}

A proposta da técnica de ensino utilizada na disciplina em análise procura inserir os alunos em ambientes tecnológicos, por meio das startups participantes do projeto. Os alunos conhecem as startups e desenvolvem no decorrer do semestre um conjunto de instrumentos e contatos que podem auxiliar a empresa em seu desenvolvimento. Esse auxílio corrobora a proposta de Menck e Oliveira Filho (2009) de que a universidade pode apoiar os empreendimentos tecnológicos ao redor da universidade.

A análise dos documentos evidenciou que os alunos relatam que proporcionaram benefícios para as startups participantes enquanto cursavam a disciplina, sendo os mais relevantes nos 5 anos analisados a "Elaboração e Revisão do Canvas", o "Contato com diversos investidores anjos" que apoiam com mentorias gerenciais para melhorias no negócio, e a "Elaboração do Pitch". Ademais, os relatos reforçam o apoio no desenvolvimento de instrumentos que auxiliam na divulgação da empresa.

De forma complementar, a partir da análise dos relatórios observou-se a relevância do projeto para as startups envolvidas. Por meio dos relatos verifica-se que as empresas, além de utilizarem as ferramentas desenvolvidas pelos alunos, tiveram uma experiência de reflexão das próprias estratégias. Desse modo, as startups são beneficiadas nesse projeto, o que as auxilia a enfrentar os desafios inerentes de sua origem e tamanho como evidenciado Oakey (2012) e Porto (2013).

Cabe salientar que a TME é uma técnica que conseguiu estabelecer o alinhamento entre o ensino de matérias técnicas e gerenciais, sendo essa uma das barreiras do ensino do Empreendedorismo Tecnológico, conforme aponta Kelley, Singer e Ilerrington (2011). 


\section{A TÉCNICA MULTIDIMENSIONAL DE ENSINO E OS BENEFÍCIOS PROPORCIONADOS ÀS

Tal fator contribui para além dos alunos, mas também para a sociedade empresarial, visto que a universidade, portanto, desenvolve seu papel social de moldar sujeitos capacitados e éticos, possibilitando um retorno concreto para as startups envolvidas. Mais especificamente, as startups podem obter profissionais capacitados não somente nas áreas técnicas, mas também em corpo profissional capaz de instruir e gerenciar esse novo modelo organizacional que sofre com problemas gerenciais diversos devido aos aspectos de sua pequenez e novidade (STOKAN; THOMPSOM; MAHU, 2015). Ademais, a universidade reforça seu papel de incentivadora e apoiadora de startups, que são peça chave para o cenário global na percepção de Porto (2013).

\section{CONSIDERAÇÕES FINAIS}

O objetivo desse estudo foi analisar o retorno da TME para as startups (sociedade), a partir da opinião dos alunos que cursaram a disciplina de Empreendedorismo Tecnológico do Curso de Administração na Universidade Federal de Itajubá (UNIFEI) entre 2012 a 2016. Para tanto, estabeleceu-se os seguintes objetivos específicos: (i) Avaliar a opinião dos alunos sobre o retorno à sociedade no momento da disciplina; e (ii) Avaliar a opinião dos alunos sobre o retorno à sociedade após terem cursado a disciplina.

Para o primeiro objetivo específico foi analisado os relatórios entregues pelos alunos. Foi analisado o tópico benefícios para as startups. Os resultados mais relevantes foram "Elaboração e Revisão do Canvas", o "Contato com diversos investidores anjos", e a “Elaboração do Pitch”, além de evidências de auxílio na divulgação da empresa.

O segundo objetivo específico, foi alcançado por meio da análise multivariada. Os resultados advindos da análise de cluster e da análise discriminante apresentaram dois grupos distintos. O Cluster 1 foi denominado "Concordantes" e o Cluster 2 denominado "Discordantes" às implicações da TME para a sociedade.

Após a análise dos resultados observa-se que houve implicações da TME para a sociedade, sendo avaliadas como positivas pelos alunos. Entre os resultados mais significativos estão: as conversas com investidores anjos ajudaram na gestão da empresa, melhoria do modelo de negócio ou plano de negócio, e a troca de experiências entre alunos, empresas e investidores anjo proporcionaram benefícios para as partes envolvidas. Ademais, a TME proporcionou aos estudantes uma aprendizagem fora da sala de aula, além do estreitamento entre teoria e prática. 
Vale destacar, que os resultados evidenciam que com o amadurecimento da técnica ao passar dos anos, aumenta a aceitação dos alunos ao método, e isso é percebido pelos alunos que cursaram a disciplina nos últimos três anos com maior dedicação ao projeto. Já os primeiros alunos que cursaram a disciplina (2012 e 2013) foram indiferentes aos resultados à sociedade e se dedicaram menos ao projeto.

Diante disso, a TME mostrou-se como uma ferramenta pertinente para a formação do administrador, especificamente no contexto das startups, visto que proporcionou aos discentes aprendizagens e troca de experiências situadas em um contexto.

Entre as limitações do estudo, destaca-se somente a percepção dos alunos a técnica. Além disso, os resultados devem ser analisados com cuidado, pois são baseados em uma disciplina e não permite generalizações.

Como proposições de trabalhos futuros, sugere-se avaliar a percepção das empresas participantes, e também avaliar os resultados dessa técnica com a aplicação em diferentes contextos. Ademais, estudos futuros poderiam investigar o processo de construção da técnica, na percepção do docente que a conduziu.

\section{REFERÊNCIAS}

ANDINO, B. F; FRACASSO, E. M. Efetividade do processo de Incubação de Empresas. In.: ENCONTRO NACIONAL DA ASSOCIAÇÃO NACIONAL DA PÓS-GRADUAÇÃO E PESQUISA EM ADMINISTRAÇÃO, 29, 2005, Brasília, Anais... Brasília, 2005.

ANDRADE, J. R. G; OLAVE, M. E. L. Aprendizagem empreendedora experiencial: estudo de múltiplos casos de pequenos empreendedores sergipanos. Revista da Micro e Pequena Empresa, v. 9, n. 2, p. 44-60, 2015.

ARAÚJO, J. C. S. Fundamentos da metodologia de ensino ativa. In.: REUNIÃO NACIONAL DA ANPEd, 37, 2015, Florianópolis, Anais..., UFSC: Florianópolis, 2015.

BARDIN, L. Análise de Conteúdo. Tradução Luís Antero Reto, Augusto Pinheiro. São Paulo: Edições 70, 2016.

BERBEL, N. A. N. As metodologias ativas e a promoção da autonomia de estudantes.

Semina: Ciências Sociais e Humanas, v. 32, n. 1, p. 25-40, 2012.

BOLLINGER, L; HOPE, K; UTTERBACK, J. M. A review of literature and hypotheses on new technology-based firms. Research Policy, v. 12, n. 1, p.1-14, 1983.

BORGES, T. S; ALENCAR, G. Metodologias ativas na promoção da formação crítica do estudante: o uso das metodologias ativas como recurso didático na formação crítica do 
estudante do ensino superior. Cairu em Revista, v. 3, n.4, p.119-143, 2014.

CANDAU, V. M. A didática e a formação de educadores-da exaltação à negação: a busca da relevância. Vozes, 2012.

CHAVES, C. M. L; SILVA, M. C. M. As incubadoras de empresas como parceiras dos empreendedores - um estudo sobre as incubadoras situadas no Nordeste. In.: ENCONTRO NACIONAL DA ASSOCIAÇÃO NACIONAL DA PÓS-GRADUAÇÃO E PESQUISA EM ADMINISTRAÇÃO, 28, Curitiba, Anais..., Curitiba, 2004.

CRESWELL, J. W; CLARCK, V. L. P. Designing and Conducting Mixed Methods Research. Thousand Oaks, CA: Sage, 2006.

CUNHA, M. I. O bom professor e sua prática. Papirus Editora, 2012.

DIESEL, A; BALDEZ, A. L. S; MARTINS, S. N. Os princípios das metodologias ativas de ensino: uma abordagem teórica. Revista Thema, v. 14, n. 1, 268-288, 2017.

ENGELMAN, R; FRACASSO, E. M; BRASIL, V. S. A qualidade percebida nos serviços de incubação de empresas. Revista Eletrônica de Administração - REAd, v. 17, n. 3, 2011.

ETZKOWITZ, H; LEYDESDORFF, L. The dynamics of innovation: from National Systems and "Mode 2" to a Triple Helix of university-industry-government relations. Research Policy, v. 29, n. 2, p. 109-123, 2000.

ETZKOWITZ, H; KLOFSTEN, M. The innovating region: toward a theory of knowledgebased regional development. R \& D Management, v. 35, n. 3, p. 243-255, 2005.

FRANCISCO, T. H. A; VEFAGO, Y. B; RAMOS, A. M; SOUZA, I. R. Para além das metodologias ativas: uma reflexão sobre a indução da qualidade em cursos de Administração. Revista Brasileira de Ensino Superior, v. 3, n.2, p. 38-57, 2017.

FRANCO, M. A. S. Didática: Uma Esperança para as Dificuldades Pedagógicas do Ensino Superior? Práxis Educacional, v. 9, n. 15, p.147-166, 2013.

FRANCO, M. A. S; PIMENTA, S. G. Didática Multidimensional: por uma sistematização conceitual. Educação \& Sociedade, v. 37, n. 135, 2016.

FREIRE, J. R. S; SANTOS, I. C; SANTOS, S. A; CASTRO, A. D. M; SOARES, D. A. S. R. Empreendedorismo tecnológico como opção de segunda carreira: pós-aposentadoria. Revista de Empreendedorismo e Gestão de Pequenas Empresas, v. 3, n.2, p. 94-119, 2014.

GIMENEZ, A. M. N; BAMBINI, M. D; BONACELLI, M. B. M. Universidades no sistema de inovação brasileiro: a experiência da unicamp na promoção de uma cultura da propriedade intelectual, empreendedorismo e inovação. Cadernos de Prospecção, v. 9, n. 1, p. 18, 2016.

GODOI-DE-SOUSA, E; LOPES, J. E. F. Empreendedorismo tecnológico e startups: uma análise de cenários no contexto de universidades brasileiras. In.: ENCONTRO DE ESTUDOS 
SOBRE EMPREENDEDORISMO E GESTÃO DE PEQUENAS EMPRESAS, 9, Passo Fundo: RS, Anais..., Passo Fundo, 2016.

GOMES, G. R. S; SILVA, A. B; SANTOS, G. T; FIDELIS, S. T. S. Estilos de Aprendizagem de Alunos de Cursos de Graduação em Administração: Uma Análise Multidimensional. In.: ENCONTRO NACIONAL DA ASSOCIAÇÃO NACIONAL DE PÓS-GRADUAÇÃO E PESQUISA EM ADMINISTRAÇÃO, 39, Belo Horizonte, Anais..., Belo Horizonte, 2015.

GUERRERO, M.; URBANO, D. Las Universidades Emprendedoras en la Economía del Conocimiento. México: Pearson Educación, 2011.

HAASE, H; ARAÚJO, E. C; DIAS, J. Inovações Vistas pelas Patentes: exigências frente às novas funções das universidades. Revista Bras. de Inovação, v. 4, n. 2, p. 329-362. 2005.

HAIR JUNIOR, J. F; BLACK, W. C; BABIN, B. J., ANDERSON, R. E; TATHAM, R. L. Análise multivariada de dados. Porto Alegre: Bookman Editora, 2005.

HARTZ, A. M; SCHLATTER, G. V. A Construção do Trabalho de Conclusão do Curso por Meio da Metodologia Ativa Team-Based Learning. Revista de Administração: Ensino e Pesquisa. Rio de Janeiro, v. 17, n.1, p.73-109, 2016.

HUMMEL, K; PIFAFF, D; ROST, K. Does Economics and Business Education Wash Away Moral Judgment Competence? Journal of Business Ethics, v.1, p.1-19, 2016.

JACKSON, J; JONES, M., STEELE, W., \& COIACETTO, E. How best to assess students taking work placements? An empirical investigation from Australian urban and regional planning. Higher Education Pedagogies, v. 2, n. 1, p. 131-150, 2017.

JONES, A. Perspectives on change: a study of the multiple dimensions of changing teaching. Teaching in Higher Education, v. 19, n.2, p.170-182, 2014.

KELLEY, D. J., SINGER, S; ILERRINGTON, M. Global Entrepreneurship Monitor: 2011. Global Report. 2011. Acesso em 16 de fevereiro de 2018 de $<$ http://www.gemconsortium.org/report>.

KITCHENS, B; MEANS, T; TAN, Y. R. Captivate: Building blocks for implementing active Learning. Journal of Education for Business, v. 93, n.2, p. 58-73. 2018. DOI: $10.1080 / 08832323.2017 .1417232$

LEMOS, D. C; SARUBBI, F. M; OLIVEIRA, A. L. M; ROSA, C, T. Uma reflexão acerca do ensino das disciplinas de recursos humanos/gestão de pessoas nos cursos de graduação em administração do Estado de Santa Catarina. In.: SEMINÁRIO EM ADMINISTRAÇÃO, 14, São Paulo, Anais..., São Paulo, 2011.

MENA, E. M. I. Revisión sobre literacidad como noción multidimensional para una Didáctica de las Lenguas inclusiva. Porta Linguarum, v. 27, p.79-92, 2017.

MENCK, A. C. M; OLIVEIRA FILHO, J. B. Alternativas de implantação para novas 
empresas de base tecnológica. 2009. Recuperado em 19 fevereiro, 2018 de https://repository.icesi.edu.co/biblioteca_digital/bitstream/item/1928/1/42.pdf.

MINAYO, M. C. S. O desafio do conhecimento. Pesquisa qualitativa em saúde. 7. ed. São Paulo: Hucitec, 2000.

MITRE, S. M. et al. Metodologias ativas de ensino-aprendizagem na formação profissional em saúde: debates atuais. Ciência \& Saúde Coletiva, v. 13, n. 2, p. 2133-2144, 2018.

MOREIRA, M. A. O que é afinal aprendizagem significativa. Universidade Federal do Mato Grosso, Cuiabá, 2010.

MOWERY, D. C; SAMPAT, B. N. Universities in national innovation systems. In.: FAGERBERG, J; MOWERY, D. C; NELSON, R. R. (Orgs.). The Oxford Handbook of innovation, Oxford: Oxford University Press, 2004.

NACU, C. M; AVASILCÃI, S. Technological Entrepreneurship: Success Factors as Perceived by Potential Young Entrepreneurs. Advanced Materials Research, v. 837, p. 639644, 2014.

OAKEY, R. P. High-technology entrepreneurship. Routledge. 2012.

PASQUARELLI, B. V. L; OLIVEIRA, T. B. (2017) Aprendizagem baseada em projetos e formação de professores: uma possibilidade de articulação entre as dimensões estratégica, humana e sócio-política da didática. Enseñ Aprend Cienc, v. 12, n. 2, p. 186-203, 2017.

PORTO, G. S. Gestão da Inovação e Empreendedorismo. Rio de Janeiro. Elsevier, 2013.

RANGEL, M. Fundamentos pedagógicos: referências significativas comuns ao ensino nas áreas de estudos gerais e profissionalizantes. Boletim Téc. Senac, v. 36, n.3, p.15-23, 2010.

ROSENBERG, N; NELSON, R. R. American universities and technical advance in industry. Research Policy, v. 23, n.3, p.323-348, 1994.

SANTOS, S. A; CUNHA, N. C. V. Criação de empresas de base tecnológica: conceitos, instrumentos e recursos. São Paulo: Unicorpore, 2004.

SCHMITZ, A; ROCHADEL, W; DANDOLINI, G. A; SOUZA, J. A; GONÇALVES, A. L. Inovação, Empreendedorismo e Universidades no Programa de Pós-Graduação em Engenharia e Gestão do Conhecimento da Universidade Federal de Santa Catarina. International Journal of Knowledge Engineering and Management (IJKEM), v. 5, n. 13, p.80-98, 2016.

SNYDER, K. D. Ropes, poles, and Space. Active learning in business education. Active Learning in Higher Education, v.4, n. 2, p.159-167, 2003.

SOBRINHO, J. D. Universidade fraturada: reflexões sobre conhecimento e responsabilidade social. Avaliação: Revista da Avaliação da Educação Superior, v. 20, n. 3, 2015. 
SOUZA, C. V; SHIGUTI, W. A; RISSOLI, V. R. V. Metodologia ativa para aprendizagem significativa com apoio de tecnologias inteligentes. Nuevas ideias em Informática Educativa TISE, 2013.

STOKAN, E; THOMPSON, L; MAHU, R. J. Testing the differential effect of business incubators on firm growth. Economic Development Quarterly, v. 29, n. 4, p.317-327, 2015.

YIN, R. K. Estudo de Caso: Planejamento e Métodos. Bookman editora, 2001. 